\title{
Awareness, Treatment, and Control of Hypertension Among 10663 Adults in Kherameh: A Population- Based Study
}

\section{Abbas Rezaianzadeh}

Shiraz University of Medical Sciences

Fatemeh Jafari ( $\Delta$ m.jafarii4319@gmail.com )

Shiraz University of Medical Sciences

Seyed Ebrahim Sadeghi

Shiraz University of Medical Sciences

\section{Salar Rahimikazerooni}

Shiraz University of Medical Sciences

\section{Ehsan Bahramali}

Tehran University of Medical Sciences

Hamed Karami

Shiraz University of Medical Sciences

\section{Research Article}

Keywords: Hypertension, Awareness, Treatment, Control

Posted Date: January 28th, 2021

DOI: https://doi.org/10.21203/rs.3.rs-151499/v1

License: (1) This work is licensed under a Creative Commons Attribution 4.0 International License. Read Full License 


\section{Abstract}

Background: Hypertension (HTN) is known to be a modifiable risk factor for Cardiovascular Disease (CVDs), stroke, and kidney disease. The present study aimed to determine awareness, treatment, and control of HTN and the related factors in Kherameh, Iran.

Methods: This cross-sectional study was performed on 10663 individuals over 40 years of age using Kherameh cohort data. HTN was defined as either Systolic/Diastolic Blood Pressure (SBP/DBP) $\geq 140 / 90$ $\mathrm{mmHg}$ or taking medications. Logistic regression was used to examine the relationship between awareness, treatment, and control and their related factors.

Results: Awareness, treatment, and control rates were $80.3 \%, 78 \%$, and $53.6 \%$, respectively among the individuals with HTN. Age, gender, body mass index, and CVD were associated with all dependent variables in the regression model. In addition, occupation, diabetes, chronic diseases, history of CVD in the first- and second-degree relatives, and history of chronic diseases in the second-degree relatives were related to all dependent variables, except for treatment.

Conclusion: The results indicated that despite the high level of awareness, the proportion of patients under treatment and control gradually decreased, such a way that about half of the patients had abnormal blood pressure. Hence, educational intervention is recommended to increase the patients' awareness to ensure the continuous use of antihypertensive drugs in order to help control the disease more efficiently.

\section{Background}

Hypertension (HTN) is an important public health challenge worldwide because of its high prevalence and concomitant risks of cardiovascular and kidney diseases (1). It has been identified as the third cause of disability-adjusted life years (2) and has been reported to be directly responsible for $49 \%$ of ischemic heart diseases and $62 \%$ of cerebrovascular diseases, as the most common cause of death in developing countries (3). The number of persons living with HTN is increasing and has been projected to grow to about 1.5 billion by 2025 (4). Many studies have shown that urbanization and adaptation to the Western lifestyle, due to the economic growth and changes observed with age, have led to an epidemic of noncommunicable chronic diseases, such as $\operatorname{HTN}(5,6)$. The prevalence of HTN varies across the world considerably. Its prevalence has been reported to be $43.5 \%$ in Malaysia (7), 23.7\% in Sri Lanka (8), 30\% in sub-saharan Africa (9), and $26.21 \%$ in Iran (5).

The most important barrier to diagnosis of HTN is the lack of awareness of the disease and its complications (11). Epidemiological studies have revealed the need for increasing the awareness of HTN, especially in low- and middle-income countries where the public awareness of the disease is relatively unpleasant (10). Moreover, while HTN is a preventable disease, antihypertensive drugs are not used often (11). In a population-based survey in China, $42.6 \%$ of the patients were aware of their HTN status and $34.1 \%$ received antihypertensive treatments (12). In Vietnam, $48.4 \%$ were aware of their elevated Blood 
Pressure (BP), 29.6\% were under treatment, and 10.7\% achieved the targeted BP control (13). In Iran, $49.6 \%$ of the patients were aware, $55.7 \%$ were treated, and $69.2 \%$ were controlled (14).

A comprehensive strategy to reduce the complications of HTN should include prevention approaches, such as increasing awareness, early diagnosis, adequate treatment, and careful BP control (15). This study aims to investigate awareness, treatment, and control of HTN and their related factors based on the baseline data of Kherameh cohort study.

\section{Methods}

This cross-sectional study was performed on 10663 individuals aged 40-70 years in Kherameh cohort study during 2015-2016. Kherameh cohort study is a part of the Prospective Epidemiological Research Studies in Iran (PERSIAN), and logic, goals, and design of the PERSIAN cohort study have already been published (16).

The main purpose of Kherameh cohort study was to determine the prevalence and risk factors of noncommunicable diseases at the beginning and follow-up. Firstly, the participants filled out the informed consent forms and then, trained staff conducted the interviews and collected the data. After admission, the participants underwent laboratory and physical examinations, including measurement of height, weight, waist circumference, and BP. BP was measured after a 10-minute rest in the sitting position using a standard calibrated sphygmomanometer (Reister Model, Germany). The individuals were required not to be active, consume food or fluids, and smoke at least half an hour before the measurement. Weight was measured with minimal coverage and without shoes using a SECA scale made in Germany with an accuracy of 100 grams. Height was also measured using a measuring tape to the nearest $0.1 \mathrm{~cm}$ with light clothing and without shoes. Then, Body Mass Index (BMI) was calculated by dividing weight by height squared. Furthermore, blood glucose, triglyceride, and cholesterol tests were performed by the Mindray device (made in Japan) using Pars Azmoon kits. The individuals were required to fast for 12 hours before sampling and not to smoke or drink alcohol.

Physical activity was assessed using a questionnaire, which included sports, occupation, and the amount of time spent sleeping and eating during a day. After that, the Metabolic Equivalent Task (MET) index was computed for each activity. Finally, physical activity was divided into four groups; i.e., mild, moderate, high, and severe, based on the quartiles.

Socioeconomic Status (SES) included homeownership, home size, number of bathrooms within the house, having cars, price of the cars, domestic and international travels, and owning mobile phones, televisions, vacuum cleaners, washing machines, refrigerators, microwaves, and computers. Instead of statistically analyzing each component of the SES, exploratory factor analysis was utilized in order to generate fewer hidden factors. Accordingly, each individual was given a quantitative score at the significance level of 0.4. Additionally, education level was classified into five categories, namely illiterate, less than five years, six to eight years, high school, and academic. It should also be noted that the firstdegree relatives included father, mother, brother, sister, son, and daughter. 


\section{Definition}

According to the guideline for management of HTN in Europe, HTN was defined as Systolic BP (SBP) equal to or above $140 \mathrm{mmHg}$, Diastolic BP (DBP) equal to or above $90 \mathrm{mmHg}$, or being under treatment for HTN (17). Besides, dyslipidemia was defined as high cholesterol ( $\geq 200 \mathrm{mg} / \mathrm{dL}$ ) or high serum triglyceride levels ( $\geq 150 \mathrm{mg} / \mathrm{dL}$ ). Diabetes was defined as the history of known diabetes or fasting blood sugar $\geq 126 \mathrm{mg} / \mathrm{dL}$ (18). Moreover, awareness was regarded as the self-report of a previous diagnosis by the health staff. Finally, treatment was considered as taking antihypertensive medications and control was defined as BP less than 140/90 $\mathrm{mmHg}$.

\section{Statistical analysis}

Mean and standard deviation were used to describe quantitative variables and frequency and percentage were used for qualitative ones. Multivariate logistic regression was used to determine the relationship between the factors associated with awareness, treatment, and control of the disease. All tests were twotailed at the significance level of 0.05 and were carried out by the SPSS software, version 20.

\section{Results}

Out of the 10663 participants, 4719 (44.3\%) were male. Additionally, 4416 participants (41.4\%) lived in urban areas, $5516(51.7 \%)$ were employed, and 562 (5.3\%) had academic degrees (Table 1). The means of SBP and DBP were respectively $105.8 \pm 10$ and $67.8 \pm 7.4 \mathrm{mmHg}$ in the healthy participants, $130.3 \pm 8.5$ and $79.9 \pm 6.7 \mathrm{mmHg}$ in the pre-hypertensive ones, and $131.9 \pm 20$ and $80.2 \pm 11.9 \mathrm{mmHg}$ in the patients. 
Table 1

The demographic characteristics of

Kherameh population

\begin{tabular}{|ll|}
\hline Variables & Participants, No. (\%) \\
\hline All & $10663(100)$ \\
Sex & $4719(44.3)$ \\
Female & $5944(55.7)$ \\
\hline Age & $4639(43.5)$ \\
40-49 years & $3759(35.3)$ \\
$50-59$ years & $2218(20.8)$ \\
+60 years & \\
\hline Living place & $4416(41.4)$ \\
Urban & $6247(58.6)$ \\
Rural & \\
\hline Literacy & $5587(52.4)$ \\
Illiterate & $2676(25.1)$ \\
$<5$ years & $1136(10.7)$ \\
6-8 years & $702(6.6)$ \\
High school & $562(5.3)$ \\
Academic & \\
\hline Marital status & $9492(89)$ \\
Married & $1171(11)$ \\
Single & \\
\hline Employed & $5516(51.7)$ \\
Yes & $5147(48.3)$ \\
No & \\
\hline
\end{tabular}

Among the participants with HTN, 2374 (80.3\%) were aware of their disease, 2304 (97\%) of whom were under treatment (78\% of all patients). In addition, 1584 individuals taking antihypertensive drugs (68.7\%) had achieved BP control (53.6\% of all patients) (Fig. 1). 
Among the participants who were aware of their disease, 720 (30.32\%) had abnormal BP despite taking medications. On the other hand, 70 individuals (2.94\%) did not take medications and had abnormal BP despite being aware of the disease. Furthermore, 1584 participants $(66.72 \%)$ were taking medications and had normal BP at the time of measurement (Fig. 2).

The results of the multivariate logistic models have been summarized in Table 2. Briefly, female gender had higher odds for higher awareness compared to male gender $(O R=1.3, p=0.02)$ and was associated with better treatment $(O R=2.57, p=0.01)$ and control $(O R=1.37, p=0.04)$. In addition, older individuals had better awareness $(O R=1.05, p<0.001)$, treatment $(O R=1.05, p=0.02)$, and control $(O R=1.04, p<$ $0.001)$. BMI and cerebrovascular disease were also directly related to all three outcomes. The factors that were directly related to better awareness and control included diabetes $(O R=3.29, p<0.001 ; O R=2.66, p$ $<0.001)$, other chronic diseases $(O R=1.5, p<0.001 ; O R=1.47, p<0.001)$, family history of cardiovascular disease in the first-degree relatives $(O R=2.21, p<0.001 ; O R=1.93, p<0.001)$, and family history of cardiovascular disease in the second-degree relatives $(O R=1.41, p=0.001 ; O R=1.33, p=0.014)$. On the other hand, the variables inversely associated with awareness and control consisted of being employed $(\mathrm{OR}=0.67, \mathrm{p}=0.001 ; \mathrm{OR}=0.66, \mathrm{p}=0.002)$, consumption of alcohol $(\mathrm{OR}=0.68, \mathrm{p}=0.04 ; \mathrm{OR}=0.55, \mathrm{p}=$ $0.014)$, physical activity $(O R=0.66, p=0.003 ; O R=0.66, p=0.01)$, and history of another chronic disease in the second-degree relatives $(O R=0.5, p<0.001 ; O R=0.51, p=0.001)$. Furthermore, education level was correlated to awareness $(\mathrm{OR}=0.8, p=0.03)$ and high cholesterol level was associated with control $(\mathrm{OR}=$ $0.8, p=0.046)$. 
Table 2

The results of the multivariate logistic regression models on the factors associated with awareness, treatment, and control of hypertension

\begin{tabular}{|c|c|c|c|c|c|c|}
\hline Variables & $\begin{array}{l}\text { Awareness } \\
\text { OR [95\% } \\
\text { Cl] }\end{array}$ & $\begin{array}{l}\mathrm{P}- \\
\text { value }\end{array}$ & $\begin{array}{l}\text { Treatment } \\
\text { OR [95\% } \\
\text { Cl] }\end{array}$ & $\begin{array}{l}\mathrm{P} \text { - } \\
\text { value }\end{array}$ & $\begin{array}{l}\text { Control } \\
\text { OR } \\
{[95 \%} \\
\mathrm{Cl}]\end{array}$ & $\begin{array}{l}\mathrm{P} \text { - } \\
\text { value }\end{array}$ \\
\hline Gender & 1 & 0.02 & 1 & 0.01 & 1 & 0.04 \\
\hline $\begin{array}{l}\text { Male } \\
\text { Female }\end{array}$ & $\begin{array}{l}1.3(1.04- \\
1.63)\end{array}$ & & $\begin{array}{l}2.57 \\
(1.18- \\
5.59)\end{array}$ & & $\begin{array}{l}1.37 \\
(1.01- \\
1.87)\end{array}$ & \\
\hline Age & $\begin{array}{l}1.05 \\
(1.04- \\
1.06)\end{array}$ & $\begin{array}{l}<.001 \\
0.00\end{array}$ & $\begin{array}{l}1.05 \\
(1.009- \\
1.1)\end{array}$ & 0.02 & $\begin{array}{l}1.04 \\
(1.03- \\
1.05)\end{array}$ & $\begin{array}{l}< \\
0.001\end{array}$ \\
\hline Education level & 1 & 0.03 & - & - & - & - \\
\hline $\begin{array}{l}\text { Illiterate } \\
\text { Literate }\end{array}$ & $\begin{array}{l}0.8(0.65- \\
0.98)\end{array}$ & & & & & \\
\hline Occupation & 1 & 0.001 & - & - & 1 & 0.002 \\
\hline $\begin{array}{l}\text { Jobless } \\
\text { Employed }\end{array}$ & $\begin{array}{l}0.67 \\
(0.53- \\
0.84)\end{array}$ & & & & $\begin{array}{l}0.66 \\
(0.51- \\
0.85)\end{array}$ & \\
\hline Body mass index & $\begin{array}{l}1.09 \\
(1.06- \\
1.11)\end{array}$ & $\begin{array}{l}< \\
0.001\end{array}$ & $\begin{array}{l}1.13 \\
(1.03- \\
1.24)\end{array}$ & 0.006 & $\begin{array}{l}1.04 \\
(1.02- \\
1.07)\end{array}$ & $\begin{array}{l}<.001 \\
0.00\end{array}$ \\
\hline Consumption of alcohol & 1 & 0.04 & - & - & 1 & 0.014 \\
\hline $\begin{array}{l}\text { No } \\
\text { Yes }\end{array}$ & $\begin{array}{l}0.68 \\
(0.46- \\
0.99)\end{array}$ & & & & $\begin{array}{l}0.55 \\
(0.34- \\
0.88)\end{array}$ & \\
\hline Physical activity & 1 & 0.19 & - & - & 1 & 0.38 \\
\hline $\begin{array}{l}\text { Light } \\
\text { Moderate }\end{array}$ & $\begin{array}{l}0.84 \\
(0.66- \\
1.08)\end{array}$ & $\begin{array}{l}0.02 \\
0.003\end{array}$ & & & $\begin{array}{l}0.88 \\
(0.67- \\
1.16)\end{array}$ & $\begin{array}{l}0.13 \\
0.01\end{array}$ \\
\hline $\begin{array}{l}\text { High } \\
\text { Severe }\end{array}$ & $\begin{array}{l}0.73 \\
(0.56- \\
0.95)\end{array}$ & & & & $\begin{array}{l}0.8 \\
(0.59- \\
1.06)\end{array}$ & \\
\hline & $\begin{array}{l}0.66(0.5- \\
0.87)\end{array}$ & & & & $\begin{array}{l}0.66 \\
(0.48- \\
0.91)\end{array}$ & \\
\hline
\end{tabular}




\begin{tabular}{|c|c|c|c|c|c|c|}
\hline Variables & $\begin{array}{l}\text { Awareness } \\
\text { OR }[95 \% \\
\text { Cl] }\end{array}$ & $\begin{array}{l}\mathrm{P} \text { - } \\
\text { value }\end{array}$ & $\begin{array}{l}\text { Treatment } \\
\text { OR [95\% } \\
\text { Cl] }\end{array}$ & $\begin{array}{l}\mathrm{P}- \\
\text { value }\end{array}$ & $\begin{array}{l}\text { Control } \\
\text { OR } \\
{[95 \%} \\
\text { Cl] }\end{array}$ & $\begin{array}{l}\mathrm{P}- \\
\text { value }\end{array}$ \\
\hline $\begin{array}{l}\text { High cholesterol level } \\
\text { No } \\
\text { Yes }\end{array}$ & - & - & - & - & $\begin{array}{l}1 \\
0.8 \\
(0.64- \\
0.99)\end{array}$ & 0.046 \\
\hline $\begin{array}{l}\text { Diabetes } \\
\text { No } \\
\text { Yes }\end{array}$ & $\begin{array}{l}1 \\
3.29 \\
(2.55- \\
4.24)\end{array}$ & $\begin{array}{l}< \\
0.001\end{array}$ & - & - & $\begin{array}{l}1 \\
2.66 \\
(2.02- \\
3.51)\end{array}$ & $\begin{array}{l}< \\
0.001\end{array}$ \\
\hline $\begin{array}{l}\text { Cerebrovascular disease } \\
\text { No } \\
\text { Yes }\end{array}$ & $\begin{array}{l}1 \\
4.98 \\
(4.01- \\
6.18)\end{array}$ & $\begin{array}{l}<.001 \\
0.001\end{array}$ & $\begin{array}{l}1 \\
5.6 \\
(1.67- \\
18.78)\end{array}$ & 0.005 & $\begin{array}{l}1 \\
4.07 \\
(3.24- \\
5.12)\end{array}$ & $\begin{array}{l}< \\
0.001\end{array}$ \\
\hline $\begin{array}{l}\text { Other chronic diseases } \\
\text { No } \\
\text { Yes }\end{array}$ & $\begin{array}{l}1 \\
1.5(1.26- \\
1.79)\end{array}$ & $\dot{0}_{0.001}$ & - & - & $\begin{array}{l}1 \\
1.47 \\
(1.21- \\
1.8)\end{array}$ & $\begin{array}{l}< \\
0.001\end{array}$ \\
\hline $\begin{array}{l}\text { History of cardiovascular disease in } \\
\text { the first-degree relatives } \\
\text { No } \\
\text { Yes }\end{array}$ & $\begin{array}{l}1 \\
2.21 \\
(1.79- \\
2.73)\end{array}$ & $\begin{array}{l}< \\
0.001\end{array}$ & - & - & $\begin{array}{l}1 \\
1.93 \\
(1.51- \\
2.46)\end{array}$ & $\begin{array}{l}<.001 \\
0.00\end{array}$ \\
\hline $\begin{array}{l}\text { History of cardiovascular disease in } \\
\text { the second-degree relatives } \\
\text { No } \\
\text { Yes }\end{array}$ & $\begin{array}{l}1 \\
1.41 \\
(1.15- \\
1.74)\end{array}$ & 0.001 & - & - & $\begin{array}{l}1 \\
1.33 \\
(1.06- \\
1.67)\end{array}$ & 0.014 \\
\hline $\begin{array}{l}\text { History of another chronic disease } \\
\text { in the second-degree relatives } \\
\text { No } \\
\text { Yes }\end{array}$ & $\begin{array}{l}1 \\
0.5(0.35- \\
0.72)\end{array}$ & $<_{0.001}$ & - & - & $\begin{array}{l}1 \\
0.51 \\
(0.33- \\
0.76)\end{array}$ & 0.001 \\
\hline
\end{tabular}

\section{Discussion}

In Iran, HTN has been the second leading cause of morbidity and mortality since $1990(19,20)$. In this country, the prevalence of HTN has been estimated to range from $27.7 \%$ (21) to $42.7 \%$ (22). Effective 
control of people with HTN requires improving awareness among health professionals and the general public.

Unlike other studies, the patients were more aware of their disease in the present investigation (80.3\%) (23). In addition, $78 \%$ of the hypertensive patients and $97 \%$ of those who were aware of their disease were treated. In other studies, these measures were found to be $40.9 \%(24)$ and $51.9 \%(25)$, respectively.

In the current research, BP was controlled in $53.6 \%$ of all patients and in $68.7 \%$ of those taking drugs. These values were similar to those of the study by Gandomkar et al. (69.1\%) (14), but higher than those obtained by Li (23). Similar results were also obtained in a survey performed on the people aged 65-94 years in Germany. In that study, $80.2 \%$ of the patients knew that they had HTN and $74.4 \%$ of the patients and $92.8 \%$ of the informed individuals took antihypertensive drugs (26). The higher awareness in the present study might result from a better access to health care. Besides, the better treatment and control of the disease in this study compared to other studies might be due to the fact that a larger number of people followed the treatment plan because of the larger population that was aware of their disease. In one study, poor treatment status was mentioned due to lower SES, lower health literacy, and misconceptions about treatment (27). Given that about half of the patients had abnormal or uncontrolled $\mathrm{BP}$, it could be justified that poor control of the disease was related to individual factors (asymptomatic disease and misconceptions) as well as health system factors (lack of antihypertensive drugs, long distance to medical centers, high cost of medicine, and shortage of skills and resources) (28).

In the present study, $19.2 \%$ of the patients were unaware of their status. Among the hypertensive patients who were aware of their disease and were taking medications, $66.72 \%$ had their disease controlled, but $30.32 \%$ had abnormal BP. Among those who did not take medications despite being aware of the disease, $2.94 \%$ had abnormal BP, which was on the contrary to the results of other investigations. Identifying the information of each of these subgroups might help researchers make better decisions to find the reason for not taking medications or controlling the disease and to find a solution for it.

The present study results showed that awareness, treatment, and control of HTN were higher among females and older individuals. These findings were consistent with those of other studies $(22,29)$, and might be due to the fact that these groups often refer to health centers to receive services (30).

In the present survey, education level was inversely associated with awareness, which was in line with the findings of the research by Malekzadeh (22). However, another study demonstrated that literacy was associated with better treatment (31). The inverse relationship might be due to the lower utilization of health services by the highly educated groups (32).

In the current study, physical activity was associated with awareness and control, while Rajati reported that it was only associated with treatment (33). In addition, higher BMI was directly related to all three outcomes. The higher level of awareness in obese people might result from receiving more attention from the health system (34). 
In agreement with the current study findings, Zhang indicated that better disease control was inversely related to high cholesterol level (35). In addition, the present study findings revealed that the individuals who drank alcohol had lower awareness about their status, which was in line with the results obtained by Lv et al. (36).

The results of a previous research indicated that the patients with diabetes had higher awareness (35), which was consistent with the results of the current study. This study also showed that the individuals with a history of cardiovascular disease had higher awareness and better treatment and control, which was in agreement with the results of the study performed by Gandmakar et al. (31). Having other chronic diseases was associated with higher awareness and better control, too. In one study, people with diabetes, obesity, heart disease, and stroke were more likely to see a doctor and have their BP checked (26). In the present study, the patients who had a history of cardiovascular disease in their first- and second-degree relatives had higher awareness and better control. Nonetheless, the awareness and control levels were $50 \%$ lower among the individuals with a family history of chronic diseases in comparison to those without this condition. The findings of two prior studies showed that the people with a family history of HTN had a higher level of awareness $(25,37)$. This might imply that a family history of HTN might encourage people to check their BP. Physicians might also pay more attention to this group because they are at a higher risk for heart diseases (38).

This study had a few limitations. First, the cross-sectional design of the study made it difficult to rule out the inverse causation of variables. HTN risk factors such as stress and dietary habits have not been analyzed. Despite these limitations, the strong points of the study included its large sample size and precise collection of data regarding the potentially relevant demographic and lifestyle factors. Also, the relationship between family history of various diseases has been investigated while it has been less seen in other studies.

\section{Conclusion}

The findings of this study indicated that despite the high level of awareness, the proportion of patients under treatment and control gradually decreased, such a way that about half of the patients had abnormal BP. Thus, educational intervention was recommended to increase the awareness of the patients who were unaware of their disease to ensure the continuous use of antihypertensive drugs in order to help control the disease more efficiently.

\section{Abbreviations}

HTN: Hypertension

CVD: Cardiovascular Disease

BP: Blood Pressure 
PERSIAN: Prospective Epidemiological Research Studies in Iran

BMl: Body Mass Index

MET: Metabolic Equivalent Task

SES: Socioeconomic Status

SBP: Systolic Blood Pressure

DBP: Diastolic Blood Pressure

\section{Declarations}

\section{Ethics approval and consent to participate}

This study was approved by the Ethics Committee of Shiraz University of Medical Sciences with IR.SUMS.REC.1397.911. All methods were performed in accordance with the relevant guidelines and regulations. All participants were informed about the purpose of the study and informed written consent was obtained from all participants and from a legal guardian in case of illiterate participants in the study.

\section{Consent for publication}

Not applicable.

\section{Availability of data and materials}

The datasets used and/or analyzed during the current study are available from the corresponding author on reasonable request.

\section{Competing interests}

The authors declare that they have no competing interests.

\section{Funding}

Not applicable.

\section{Authors' contributions}

AR contributed to the conception and design of the study, critical revision of the manuscript. FJ contributed to data analysis and interpretation, and writing up the manuscript. SS and SR contributed to design of the study and data collection. EB contributed to design of the study and HK contributed writing up the manuscript. All authors read and approved the final version of the manuscript.

\section{Acknowledgement}


The authors would like to thank Ms. A. Keivanshekouh at the Research Improvement Center of Shiraz University of Medical Sciences for improving the use of English in the manuscript.

\section{References}

1. Kearney PM, Whelton M, Reynolds K, Muntner P, Whelton PK, He J. Global burden of hypertension: analysis of worldwide data. Lancet (London, England). 2005;365(9455):217-23.

2. Ismail IM, Kulkarni AG, Kamble SV, Borker SA, Rekha R, Amruth M. Prevalence of hypertension and its risk factors among bank employees of Sullia Taluk, Karnataka. Sahel Medical Journal. 2013;16(4):139-43.

3. Montazerifar F, Karajibani M, Abbasi M, Bolouri A. Prevalence of Obesity and Hypertension and Related Factors among Bank Employees in Zahedan, 2017. International Journal of Epidemiologic Research. 2019;6(4):164-70.

4. Tianyi FL, Agbor VN, Njamnshi AK. Prevalence, awareness, treatment, and control of hypertension in Cameroonians aged 50 years and older: A community-based study. Health science reports. 2018;1(5):e44.

5. Aghaei Meybodi HR, Khashayar P, Rezai Homami M, Heshmat R, Larijani B. Prevalence of hypertension in an Iranian population. Renal failure. 2014;36(1):87-91.

6. Bahrami H, Sadatsafavi M, Pourshams A, Kamangar F, Nouraei M, Semnani S, et al. Obesity and hypertension in an Iranian cohort study; Iranian women experience higher rates of obesity and hypertension than American women. BMC public health. 2006;doi:10.1186/1471-2458-6-158.

7. Naing C, Yeoh PN, Wai VN, Win NN, Kuan LP, Aung K. Hypertension in Malaysia: An Analysis of Trends From the National Surveys 1996 to 2011. Medicine. 2016;95(2):e2417.

8. Katulanda P, Ranasinghe P, Jayawardena R, Constantine GR, Rezvi Sheriff M, Matthews DR. The prevalence, predictors and associations of hypertension in Sri Lanka: a cross-sectional population based national survey. Clinical and Experimental Hypertension. 2014;36(7):484-91.

9. Ataklte F, Erqou S, Kaptoge S, Taye B, Echouffo-Tcheugui JB, Kengne AP. Burden of undiagnosed hypertension in sub-saharan Africa: a systematic review and meta-analysis. Hypertension (Dallas, Tex: 1979). 2015;65(2):291-8.

10. Saeed AA, Al-Hamdan NA, Bahnassy AA, Abdalla AM, Abbas MA, Abuzaid LZ. Prevalence, Awareness, Treatment, and Control of Hypertension among Saudi Adult Population: A National Survey. International journal of hypertension. 2011;doi:10.4061/2011/174135.

11. Chimberengwa PT, Naidoo M. Knowledge, attitudes and practices related to hypertension among residents of a disadvantaged rural community in southern Zimbabwe. PloS one. 2019;14(6):e0215500.

12. Wang J, Zhang L, Wang F, Liu L, Wang H. Prevalence, awareness, treatment, and control of hypertension in China: results from a national survey. American journal of hypertension. 2014;27(11):1355-61. 
13. Son PT, Quang NN, Viet NL, Khai PG, Wall S, Weinehall L, et al. Prevalence, awareness, treatment and control of hypertension in Vietnam-results from a national survey. Journal of human hypertension. 2012;26(4):268-80.

14. Gandomkar A, Poustchi H, Malekzadeh F, Malekzadeh MM, Moini M, Moghadami M, et al. Prevalence, Awareness, Treatment, Control, and Correlates of Hypertension in the Pars Cohort Study. Archives of Iranian medicine. 2018;21(8):335-43.

15. Karmakar N, Nag K, Saha I, Parthasarathi R, Patra M, Sinha R. Awareness, treatment, and control of hypertension among adult population in a rural community of Singur block, Hooghly District, West Bengal. Journal of education and health promotion. 2018;7:134.

16. Poustchi H, Eghtesad S, Kamangar F, Etemadi A, Keshtkar A-A, Hekmatdoost A, et al. Prospective epidemiological research studies in Iran (the PERSIAN Cohort Study): rationale, objectives, and design. American journal of epidemiology. 2018;187(4):647-55.

17. Williams B, Mancia G, Spiering W, Agabiti Rosei E, Azizi M, Burnier M, et al. 2018 ESC/ESH Guidelines for the management of arterial hypertension: The Task Force for the management of arterial hypertension of the European Society of Cardiology (ESC) and the European Society of Hypertension (ESH). European heart journal. 2018;39(33):3021-104.

18. Gupta R, Deedwania PC, Achari V, Bhansali A, Gupta BK, Gupta A, et al. Normotension, prehypertension, and hypertension in urban middle-class subjects in India: prevalence, awareness, treatment, and control. American journal of hypertension. 2013;26(1):83-94.

19. Forouzanfar MH, Sepanlou SG, Shahraz S, Dicker D, Naghavi P, Pourmalek F, et al. Evaluating causes of death and morbidity in Iran, global burden of diseases, injuries, and risk factors study 2010. Archives of Iranian medicine. 2014;17(5):304-20.

20. Naghavi M, Shahraz S, Sepanlou SG, Dicker D, Naghavi P, Pourmalek F, et al. Health transition in Iran toward chronic diseases based on results of Global Burden of Disease 2010. Archives of Iranian medicine. 2014;17(5):321-35.

21. Rezaianzadeh A, Jafari F, Sadeghi SE, Rahimikazerooni S. The prevalence and predictors of prehypertension and hypertension in Kherameh cohort study: a population based study on 10,663 persons in south of Iran. Journal of human hypertension. 2020:1-8.

22. Malekzadeh MM, Etemadi A, Kamangar F, Khademi H, Golozar A, Islami F, et al. Prevalence, awareness and risk factors of hypertension in a large cohort of Iranian adult population. Journal of hypertension. 2013;31(7):1364-71.

23. Li W, Gu H, Teo KK, Bo J, Wang Y, Yang J, et al. Hypertension prevalence, awareness, treatment, and control in 115 rural and urban communities involving 47000 people from China. Journal of hypertension. 2016;34(1):39-46.

24. Wang L, Li N, Heizhati M, Abulikemu S, Zhang D, Luo Q, et al. Prevalence, Awareness, Treatment, Control, and Related Factors of Hypertension among Tajik Nomads Living in Pamirs at High Altitude. International journal of hypertension. 2020;https://doi.org/10.1155/2020/5406485. 
25. Pakzad B, Akbari M, Baberi F. Prevalence, awareness, treatment, and control of hypertension in an Isfahan state institution sample. The Journal of Tehran University Heart Center. 2018;13(2):65-72.

26. Muli S, Meisinger C, Heier M, Thorand B, Peters A, Amann U. Prevalence, awareness, treatment, and control of hypertension in older people: results from the population-based KORA-age 1 study. BMC Public Health. 2020;20(1):1-10.

27. Devkota S, Dhungana RR, Pandey AR, Bista B, Panthi S, Thakur KK, et al. Barriers to treatment and control of hypertension among hypertensive participants: a community-based cross-sectional mixed method study in municipalities of Kathmandu, Nepal. Frontiers in cardiovascular medicine. 2016;3:26.

28. Sanuade OA, Boatemaa S, Kushitor MK. Hypertension prevalence, awareness, treatment and control in Ghanaian population: Evidence from the Ghana demographic and health survey. PloS one. 2018;13(11):e0205985.

29. Jenson A, Omar AL, Omar MA, Rishad A, Khoshnood K. Assessment of hypertension control in a district of Mombasa, Kenya. Global public health. 2011;6(3):293-306.

30. Khanal MK, Dhungana RR, Bhandari P, Gurung Y, Paudel K. Prevalence, associated factors, awareness, treatment, and control of hypertension: Findings from a cross sectional study conducted as a part of a community based intervention trial in Surkhet, Mid-western region of Nepal. PloS one. 2017;12(10):e0185806.

31. Gandomkar A, Poustchi H, Malekzadeh F, Malekzadeh MM, Moini M, Moghadami M, et al. Prevalence, awareness, treatment, control, and correlates of hypertension in the pars cohort study. Archives of Iranian medicine. 2018;21(8):335-43.

32. Motlagh SN, Sabermahani A, Hadian M, Lari MA, Mahdavi MRV, Gorji HA. Factors affecting health care utilization in Tehran. Global journal of health science. 2015;7(6):240-49.

33. Rajati F, Hamzeh B, Pasdar Y, Safari R, Moradinazar M, Shakiba E, et al. Prevalence, awareness, treatment, and control of hypertension and their determinants: Results from the first cohort of noncommunicable diseases in a Kurdish settlement. Scientific reports. 2019;9(1):1-10.

34. O'Rourke M. Arterial stiffness, systolic blood pressure, and logical treatment of arterial hypertension. Hypertension (Dallas, Tex: 1979). 1990;15(4):339 - 47.

35. Zhang F-L, Guo Z-N, Xing Y-Q, Wu Y-H, Liu H-Y, Yang Y. Hypertension prevalence, awareness, treatment, and control in northeast China: a population-based cross-sectional survey. Journal of human hypertension. 2018;32(1):54-65.

36. Lv X, Niu H, Qu Y, Li M, Li L, Ma X, et al. Awareness, treatment and control of hypertension among hypertensive patients aged 18 to 59 years old in the northeast of China. Scientific reports. 2018;8(1):1-10.

37. Yang L, Yan J, Tang X, Xu X, Yu W, Wu H. Prevalence, awareness, treatment, control and risk factors associated with hypertension among adults in southern China, 2013. PloS one. 2016;11(1):e0146181. 
38. Tian S, Dong G-H, Wang D, Liu M-M, Lin Q, Meng X-J, et al. Factors associated with prevalence, awareness, treatment and control of hypertension in urban adults from 33 communities in China: the CHPSNE Study. Hypertension Research. 2011;34(10):1087-92.

\section{Figures}

\section{Control}

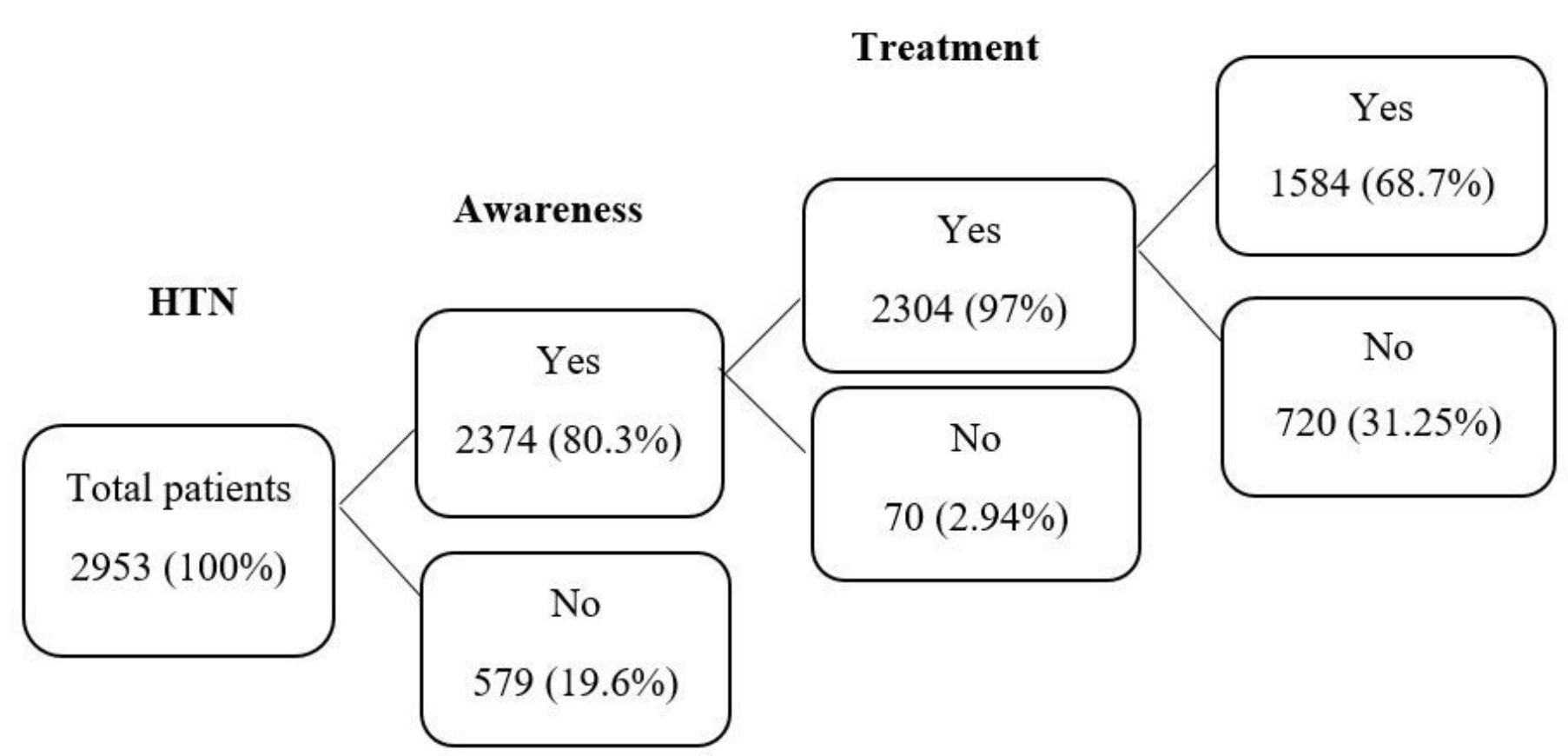

Figure 1

The flow diagram of the frequency, awareness, treatment, and control of hypertension in Kherameh population 
$66.72 \%$

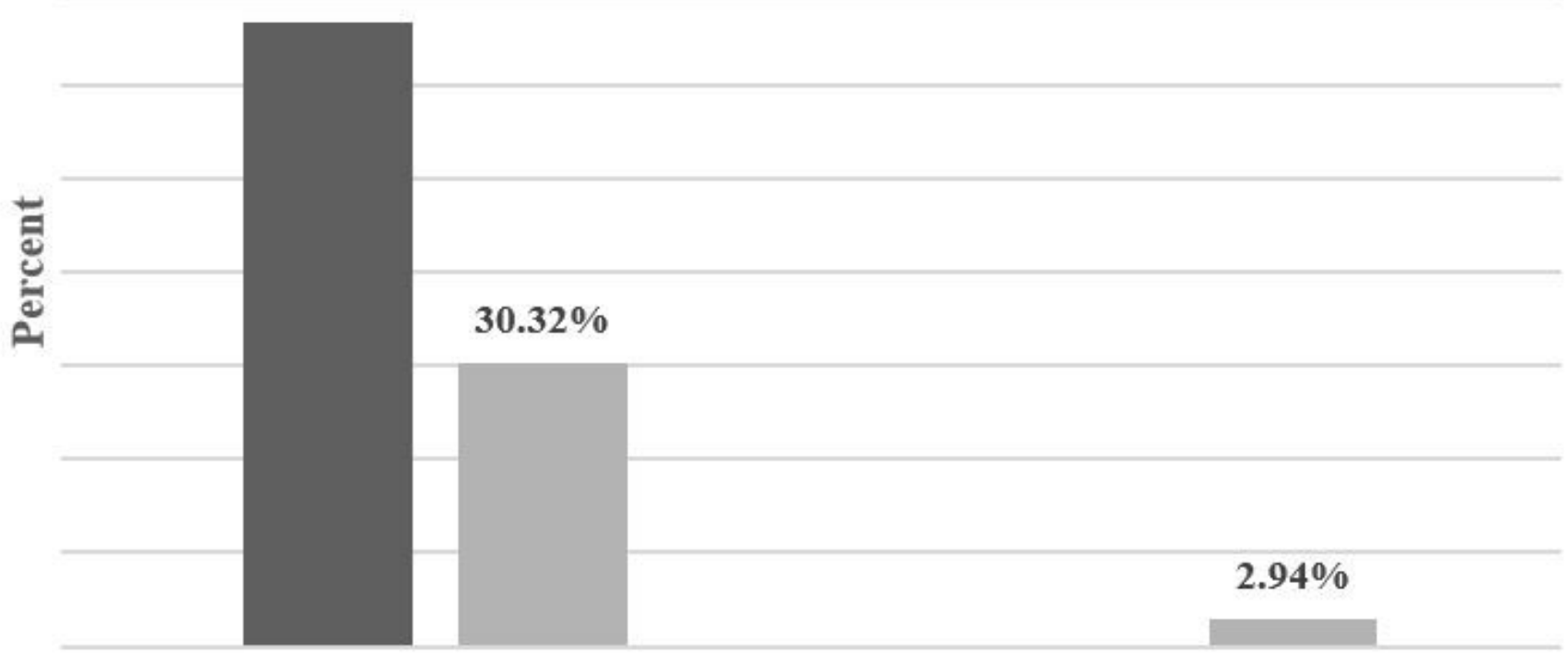

Taking medication

Not taking medication

normal blood pressure

Abnormal blood pressure

\section{Figure 2}

The percentage of the people under treatment and control among those who were aware of their disease $(n=2374)$ 